\title{
Job Design and the Employee Innovation Process: The Mediating Role of Learning Strategies
}

\author{
David Holman - Peter Totterdell • Carolyn Axtell • \\ Chris Stride - Rebecca Port • Ruth Svensson • \\ Lara Zibarras
}

(C) Springer Science+Business Media, LLC 2011

\begin{abstract}
Purpose The purpose of this article is to examine whether employee learning strategies is a mechanism through which job design affects the employee innovation process. In particular, we test whether work-based learning strategies mediate the relationship between job design characteristics (job control and problem demand) and key components of the innovation process (idea generation, idea promotion, and idea implementation).

Design/Methodology/Approach Data were collected from a survey of 327 employees in a UK manufacturing organization.

Findings Structural equation modeling confirmed the mediating role of learning strategies in the relationship between job design and idea generation. The effects of job control on idea generation were mediated by work-based learning strategies and the effects of problem demand on idea generation were partially mediated by work-based
\end{abstract}

D. Holman $(\bowtie)$

Manchester Business School, University of Manchester,

Manchester M15 6PB, UK

e-mail: david.holman@mbs.ac.uk

P. Totterdell · C. Axtell · C. Stride

Institute of Work Psychology, University of Sheffield,

Sheffield S10 2TN, UK

R. Port

Standard Chartered Bank, Marina Bay Financial Centre 8 Marina

Boulevard, Singapore 018981, Singapore

R. Svensson

KPMG, 8 Salisbury Square, London, EC4Y 8BB, UK

L. Zibarras

Department of Psychology, City University,

Northampton Square, London EC1V 0HB, UK learning strategies. Problem demand also had a direct relationship with idea generation and idea promotion. The findings provide support for the general idea that learning is a mechanism thorough which job design affects outcomes. Implications The results of the study show practitioners that creating jobs with high control or high problem demand can help to promote the employee innovation process; and that this is partly due to the role that such jobs play in stimulating the use of learning strategies at work. Originality/Value This article develops and tests a new theoretical model that explains how learning is a route through which job design influences employee innovation.

Keywords Job design - Employee learning strategies . Employee innovation process

\section{Introduction}

Job design research has sought to establish the mechanisms through which job characteristics affect employee outcomes such as performance and well-being. Employee learning has been proposed as one such mechanism (Parker and Wall 1999). The basic premise of the job design-learning mechanism is that job characteristics stimulate the learning process. This leads to the acquisition of knowledge about the job and its context, enabling the employee to perform more effectively and to cope better with demand. An additional benefit of the employee being able to cope better with demand is an improvement in well-being (Frese and Zapf 1994; Karasek and Theorell 1990). Consistent with this view, studies have found support for a job designlearning mechanism in relation to two employee outcomes, task performance (Wall et al. 1992), and well-being (Holman and Wall 2002; Taris and Kompier 2005). 
The job design-learning mechanism has yet to be established in relation to employee innovation, the individual-level process by which new ideas are generated, promoted, and implemented within organizations (Kanter 1988; Rank et al 2004; Van de Ven et al. 1989). It is important to know that job design affects employee innovation via its influence on learning because, if true, it demonstrates a route through which employee innovation can be cultivated. Organizations might therefore be able to promote employee innovation by combining effective job designs with interventions to enhance employee learning. It is also important to know the route through which job design affects employee innovation because, if the causal pathways that lead to employee innovation are similar to those that promote employee performance and well-being (i.e., a job design-learning mechanism), then organizations may be able to achieve multiple beneficial outcomes by concentrating resources and interventions on improving their common antecedents.

Encouragingly, there is empirical evidence to suggest that employee learning might be a mechanism through which job design affects employee innovation. This is because studies have shown that job design characteristics, such as job control, are associated directly with employee learning (Bond and Flaxman 2006; Leach et al. 2003; Taris and Kompier 2005) that employee learning is associated directly with innovation (Jansen and Van Yperen 2004) and that job characteristics are associated directly with employee innovation (Axtell et al. 2000; Janssen 2000; Scott and Bruce 1994). However, from these studies, it cannot be inferred directly that employee learning is a mechanism through which job design affects employee innovation. For example, studies focusing on employee learning and innovation might have found a relationship because of a common but unmeasured antecedent, i.e., job design. This means that employee learning may not be a precursor of innovation or a route through which job design influences innovation. Current studies therefore tell us little about the precise way in which job design affects learning and innovation simultaneously. As such, this article focuses on whether learning is a mechanism through which job design affects innovation.

A further feature of research on the job design-learning mechanism is that studies have typically used proxy measures of learning, such as skill utilization and self-efficacy (Holman and Wall 2002; Parker and Sprigg 1998), or assessed learning using measures of knowledge change (Bond and Flaxman 2006; Leach et al. 2003). Research in this area has yet to focus on how employees learn, i.e., the learning process. We therefore know little about how job design shapes the learning process or how the learning process affects the relationship between job design and employee outcomes. Consequently, we focus on work-based learning strategies, a key component of the learning process. These strategies are the cognitive and behavioral practices that employees use to acquire and organize knowledge at work (Holman et al. 2001; Warr and Allan 1998).

Given these gaps in the current literature on the job design-learning mechanism, the main aim of this article is to examine whether employee learning strategies is a mechanism through which job design affects employee innovation. To meet this aim, a theoretical model of the relationship between job design, work-based learning strategies, and employee innovation is developed and tested. This model advances our theoretical understanding of the route through which job design affects employee innovation, and our understanding of the job designlearning mechanism, by integrating a range of diverse perspectives (e.g., action theory, self-regulation learning theory, and theories of creativity and innovation) in order to explain how job characteristics influence the learning process (i.e., learning strategies) and how the learning process shapes employee innovation. In addition to this theoretical contribution, the article is the first to test the relationship between job design and learning strategies and the first to test the job design-learning mechanism in relation to innovation. The article therefore provides new insights into how job design shapes the processes of learning and innovation at work. The study is also of practical importance as it indicates the types of job characteristics that may foster employee learning and innovation; and highlights the learning strategies that are beneficial for employees to use.

At this point, it is useful to define and justify the use of the key constructs used in this study pertaining to job design, learning, and innovation. Job design is concerned with the characteristics of an employee's job (Parker and Wall 1999) and although a wide variety of job characteristics have been identified (Morgeson and Humphrey 2006), we focus on problem demands (i.e., the frequency and difficulty of task problems) and job control, i.e., the level of discretion an employee has over the timing of work tasks and methods used in work tasks (Jackson et al. 1993). We selected these job characteristics as they are considered to be prerequisites for learning within action theory (Frese and Zapf 1994; Hacker et al. 1968), within the job design literature (Karasek 1979; LePine et al. 2004), and because they have been proposed as antecedents of innovation (Farr 1990).

Individual learning consists of a number of different elements, including motives, learning strategies, and outcomes such as knowledge. We chose to examine workbased learning strategies because self-regulation theories of learning suggest that they may play a key role shaping the learning process (Pintrich 2000). Work-based learning 


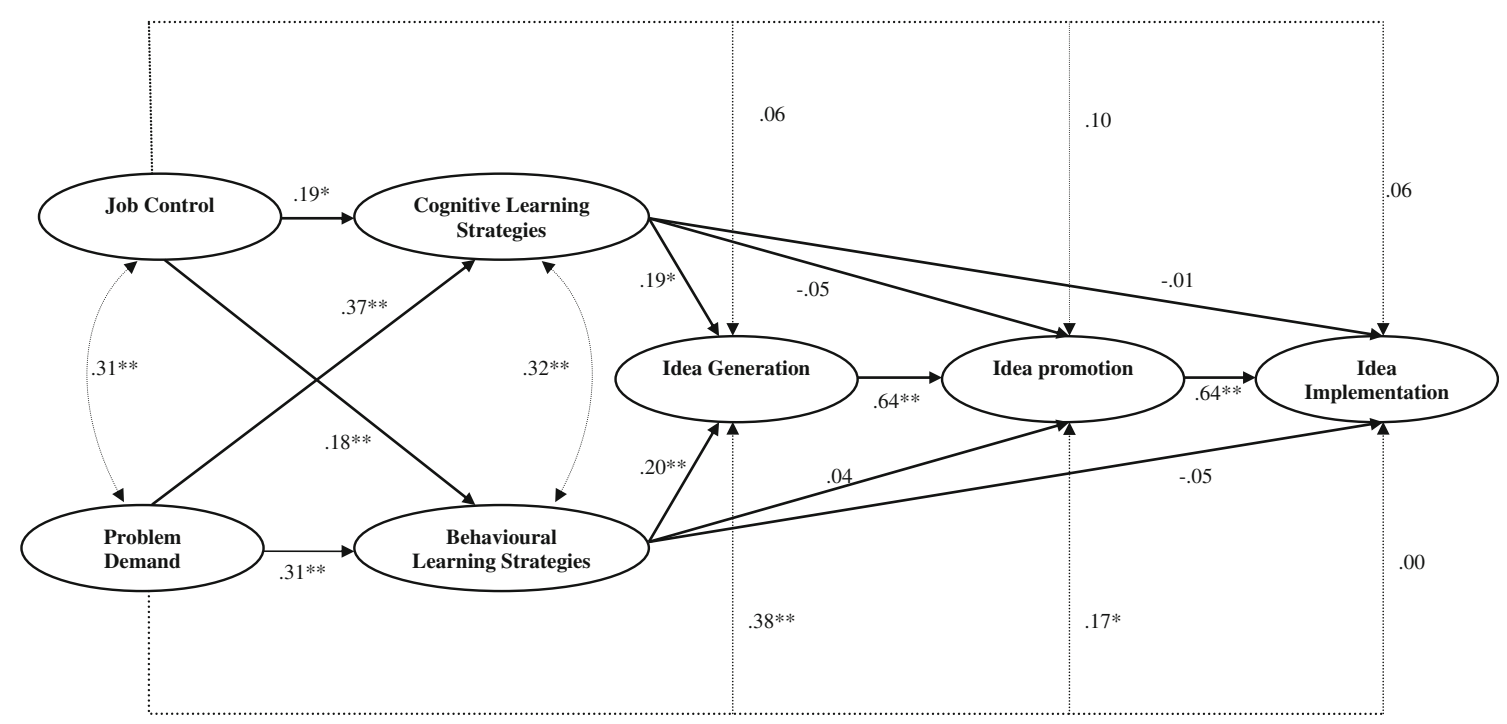

Fig. 1 Theoretical model of job design, learning strategies and innovation and results for Model 1. Note: Dark lines represent hypothesized paths. Dashed lines represent paths included for

strategies are the cognitive and behavioral practices that employees use to acquire and organize knowledge at work (Holman et al. 2001). ${ }^{1}$ There are two broad categories of work-based learning strategy (Warr and Allan 1998). Cognitive work-based learning strategies involve the elaboration of new information (examining the implications of new information in the light of existing knowledge) and the organization of new information (identifying key issues and principles and creating schemas). Behavioral work-based learning strategies include the acquisition of knowledge from coworkers, written material (e.g., training manuals), and the practical application of ideas.

Models of employee innovation view it as starting with idea generation, i.e., the creation of new ideas by employees that are intended to be useful (Janssen 2000; Rank et al. 2004). We define an idea as being new if it is new to a particular context, and such ideas can differ in terms of scale and originality. New ideas can therefore be copied from elsewhere and concern small changes or they can be highly novel ideas concerned with large-scale change. The concept of idea generation is very similar to that of creativity (Amabile 1996; Rank et al. 2004). However, within the employee innovation literature, idea generation is typically seen to include ideas that are new in a context but not very original, as well as ideas that are new and highly original; whereas creativity is seen to just include highly original ideas. After idea generation, the innovation process is progressed further by idea promotion,

\footnotetext{
${ }^{1}$ Primary learning strategies used directly with the material to be learnt can be distinguished from "support" strategies used to regulate motives, affect, or beliefs during the learning process (Dansereau 1985).
}

mediation testing in Model 1. Standardized path coefficients from Model 1; ${ }^{*} p<0.05,{ }^{*} p<0.01$; Paths to contentment and controls not shown

i.e., suggesting ideas to others, persuading others to adopt new ideas and gaining support for ideas; and it is aided by idea realization, i.e., introducing a new idea in a systematic way and obtaining resources to aid implementation. The innovation process ends with idea implementation, a new idea being integrated within organizational processes or products. In order to capture the key components of the beginning, middle, and end of the innovation process we decided to concentrate on, respectively, idea generation, idea promotion, and idea implementation.

\section{Theory and Hypotheses: The Job Design-Learning Mechanism and Employee Innovation}

Arguments for a job design-learning mechanism assert that learning is a mechanism through which job design affect employee outcomes. Given the focus of this article, our theoretical justification of a job design-learning mechanism in relation to innovation needs to explain how job characteristics affect work-based learning strategies, and how work-based learning strategies affect innovation. We set out this theoretical justification below and our model can be seen in Fig. 1 .

\section{The Effects of Job Design on Work-Based Learning Strategies}

The first part of our theoretical model of the job designlearning mechanism proposes that problem demands and job control will stimulate the use of work-based learning strategies. One explanation for the effects of problem 
demands on learning strategies is that task problems prevent employees from attaining goals such as effective task performance. In response, employees will be motivated to deploy strategies that have the potential to aid goal attainment and problem solving (Frese and Zapf 1994) such as work-based learning strategies. For example, cognitive learning strategies are a means with which employees can understand the basic principles of a problem, while behavioral learning strategies are a means with which employees are able obtain information from others to help resolve a problem. The use of work-based learning strategies does not guarantee problem resolution but they may make it more likely.

Another explanation for the effects of problem demand on learning strategies draws on the idea of job challenge demands (McCauley et al. 1994; Podsakoff et al. 2007). Job challenge demands are defined as demands that are appraised as having the potential to promote personal growth and achievement; and because of this positive appraisal, challenge demands trigger problem-focused coping approaches such as increased effort (i.e., motivation) and attempts to acquire knowledge and new behaviors (Cavanaugh et al. 2000; LePine et al. 2004). Challenge demands include workload, job scope, task difficulty, responsibility, and cognitive demands. LePine et al. (2004) used expectancy theory to propose that these types of demand come to be appraised as positive challenges because, on the basis of experience, employees come to believe that they can use problem-focused coping approaches to deal with these types of demand and achieve valued outcomes, e.g., high performance, development of new skills. Indeed, it is because employees expect to achieve these valued outcomes that they are prepared to offset these gains against the possible problems associated with the effort required to meet the demand, e.g., feelings of fatigue. Importantly, empirical studies have shown that challenge demands are associated positively with task motivation and performance (LePine et al. 2005), with learning motivation and learning performance (LePine et al., 2004) and that the relationship between challenge demands and motivation is independent of the effects of other types job characteristic such as job control (Van den Broeck et al. 2010). The literature on job challenge demands therefore implies that problem demand is likely to be appraised positively as a challenge and, as such, problem demand is likely to evoke problem-focused strategies to cope with this demand, such as increased effort to acquire knowledge and the use of learning strategies to acquire knowledge. Overall, action theory and the literature on job challenge demands provide theoretical and empirical reasons to believe that, when problem demands are high, an employee may be more likely to deploy workbased learning strategies.
Job control may promote the use of work-based learning strategies in two ways. First, job control increases intrinsic task motivation (Hackman and Oldham 1980) and motivation to learn (Taris et al. 2003) which prompts employees to improve task understanding and mastery (Dweck 1999). Task understanding can be aided by the use of behavioral and cognitive learning strategies, as they are one way of acquiring task knowledge and enriching it by organizing new information within existing schemas or into new schemas. Thus, when job control is high, employees will be more motivated to use work-based learning strategies. Second, job control provides the opportunity for employees to select the most effective response to a particular type of demand (Frese and Zapf 1994). One response to task problems is to adopt a problem-solving approach which, as we have suggested, can be aided by learning strategies. Alternative responses include increasing task effort, abandoning the task, or adopting a new goal (Hockey 1997). But these alternative responses do not address the root cause of the task difficulty and may be less effective over the long term than a problem-solving approach. Overall, high job control is therefore likely to motivate and provide the opportunity to use work-based learning strategies.

To date there have been no empirical studies that have examined the effects of job design on learning strategies. However, based on the above discussion there are strong theoretical reasons to propose the following hypothesis.

Hypothesis 1 Problem demands and job control will be positively associated with cognitive and behavioral workbased learning strategies.

\section{The Effects of Work-Based Learning Strategies} on Innovation

In the second part of our theoretical model of the job design-learning mechanism, we propose that work-based learning strategies affect innovation. Our reasoning for this proposition has two steps. In the first step, learning strategies promote knowledge acquisition about the job task and context. With regard to cognitive learning strategies, dual process models of cognition posit that deliberate, intentional, and analytical modes of cognition stimulate the learning of new facts and rules and the organization of knowledge (Craik 2002; Smith and Decoster 2000). Cognitive learning strategies can be considered to be an example of deliberate and intentional modes of thinking in which time and effort is spent deliberating on a topic. As such, cognitive learning strategies are likely to promote knowledge acquisition as they enable the employee to elaborate on new information by examining the implications of new information in the light of existing knowledge, 
to organize new information within existing schemas and to identify key issues and principles. Behavioral learning strategies will also enable the employee to acquire knowledge from coworkers, from written material and through the practical application of ideas. For example, an employee may seek to acquire information by going online or by asking a more experienced colleague. In summary, both cognitive and behavioral work-based learning strategies are likely to enable employees to broaden and enrich their knowledge of the job task, task problems, and the job context

The effects of cognitive learning strategies on knowledge acquisition have yet to be studied in everyday work situations, although there is support for their relationship with knowledge acquisition in other contexts. For example, undergraduates' use of cognitive learning strategies has been shown to be associated positively with exam grades, course grades (Pintrich and Garcia 1993; Pintrich et al. 1993) and more sophisticated levels of understanding, i.e., knowledge that is organized according to basic principles rather than unrelated facts (Entwistle 2000; Marton and Saljo 1976). The effect of cognitive strategies on knowledge acquisition has been confirmed in experimental studies using direct assessments of knowledge acquisition (e.g., Fisher and Ford 1998), while Warr and Bunce (1995) found a cognitive learning strategy measure (including elaboration and organization) to be associated positively with a trainee's level of knowledge acquisition (derived from an examiner's assessment of post-training assignments).

The effects of behavioral learning strategies have not been studied in everyday work situations either, although there is evidence to indicate their relationship with knowledge acquisition. Research on social networks provides strong support for the idea that employees acquire knowledge by actively seeking it from coworkers (Borgatti and Cross 2003; Burt 2004), while Daniels et al. (2009) reported that employee's daily self-reports of learning were positively related to the extent to which they discussed problems and sought the views of others to solve problems. Furthermore, knowledge acquisition in training and workplace settings has been shown to be associated with practical application strategies, e.g., practicing skills (Burke and Day 1986; Driskell et al. 1994; Kolb and Kolb 2000; Sonnentag and Kleine 2000). Overall, theoretical and empirical evidence suggests that work-based learning strategies promote knowledge acquisition.

In the second step, it is proposed that the knowledge acquired through the use of learning strategies enhances the potential to create and generate new and useful ideas (Weisberg 1999). There are a number of theoretical perspectives to support this idea. According to Amabile's (1983) componential theory of creativity, an extensive domain relevant knowledge is a fundamental building block of the ability to generate new ideas, as it increases a person's potential to combine information in novel ways; a potential that is enhanced when a person's knowledge is organized according to general principles rather than as unrelated pieces of information (Amabile 1988; Hayes 1989). An implication from cognitive load theory is that greater knowledge decreases the load on working memory when in learning and problem-solving situations. This allows more cognitive effort to be applied to germane cognitive activities, such as the search for a solution or the development of new idea (Renkl and Atkinson 2003). Both these theories indicate that employees with a higher level of domain relevant knowledge will be more likely generate new ideas. Evidence to support such a link comes from studies showing that employees with a greater domain knowledge (e.g., expert employees) are more creative and generate more new ideas than employees with less extensive domain knowledge (Amabile and Gryskiewski 1987; Christiaans and Venselaar 2005; Ericsson 1998).

In sum, theoretical and empirical evidence indicates that employees who use a broad range of work-based learning strategies will be able to enrich their work-related knowledge and that this will, in turn, help them to generate new ideas. Consequently, an employee's use of work-based learning strategies should be positively and directly associated with one element of the innovation process, idea generation. Our second hypothesis is:

Hypothesis 2 Cognitive and behavioral work-based learning strategies will be positively associated with employee idea generation.

The knowledge acquired through work-based learning strategies may also influence the extent to which an employee promotes an idea to others and the extent to which their ideas are implemented. Drawing on self-efficacy theory, Gist and Mitchell (1992) argued that task knowledge helps to shape personal assessments of selfefficacy. In particular, employees with a broad in-depth task knowledge are likely to be confident in their ability to perform effectively and to believe in the usefulness and applicability of their knowledge (Bandura 1986, 1997). As such, the increases in task knowledge engendered by workbased learning strategies may increase employee selfefficacy; and this may make employees have greater confidence in the usefulness of their new ideas and to be more confident in promoting that idea to others. Higher self-efficacy also makes an individual more persistent in task accomplishment in challenging environments. Thus, increased self-efficacy might make the employee more likely to persist in promoting their idea, even in the face of indifference from others. Another reason why learning strategies might influence idea promotion is that the 
increases in knowledge brought about by the use of workbased learning strategies may help an employee to perceive the applicability and importance of a new idea and, as a result, an employee may be more inclined to promote that idea to others. For similar reasons, work-based learning strategies may also influence the likelihood of an idea being implemented. In particular, the increases in task knowledge and self-efficacy engendered by work-based learning strategies may make employees more persistent when trying to get their ideas implemented, especially in challenging environments. Furthermore, employees with better task knowledge maybe more likely to deal with objections from others to the implementation of an idea, thus increasing the chances that their idea would be implemented. We therefore set two further hypotheses.

Hypothesis 3 Cognitive and behavioral work-based learning strategies will be positively associated with employee idea promotion.

Hypothesis 4 Cognitive and behavioral work-based learning strategies will be positively associated with idea implementation.

\section{The Mediating Role of Work-Based Learning} Strategies

We have argued that job characteristics influence workbased learning strategies, and that work-based learning strategies affect three aspects of the employee innovation process. In other words, work-based learning strategies are a mechanism through which job characteristics affect idea generation, idea promotion, and idea implementation. As yet, no empirical evidence exists to support a job designlearning mechanism in relation to the innovation process. But evidence does exist for a job design-learning mechanism in relation to task performance and well-being. For example, Wall et al. (1992) showed that increased control for operators of new technology resulted in improved machine uptime, partly as a result of an immediate quicker response to faults and, in the longer term, by fault prevention, which is an indicator of knowledge development. Holman and Wall (2002) found that the relationship between job control and employee well-being was mediated by skill utilization, a proxy measure of learning. Given the theoretical and empirical evidence for a job design-learning mechanism, the following two hypotheses are set.

Hypothesis 5 Work-based learning strategies will mediate the relationship between job control and three aspects of the employee innovation process, namely idea generation, idea promotion, and idea implementation.
Hypothesis 6 Work-based learning strategies will mediate the relationship between problem demand and three aspects of the employee innovation process, namely idea generation, idea promotion, and idea implementation.

\section{Method}

Participants and Procedure

Data were obtained from a UK vehicle manufacturer. The total sample was 327 , representing an $80 \%$ response rate. Eighty-nine percent of the sample were shop floor employees engaged in assembling, fabrication and painting of vehicles, of whom $51 \%$ were machine operatives and $38 \%$ were skilled trade operatives, e.g., welders. Two percent were managers and $9 \%$ performed other administrative roles. All employees had the opportunity to engage in the innovation process through, for example, participation in a continuous improvement program. The average age was 37 years and $97 \%$ were male. Employees were recruited through presentations given by members of the research team. Data were collected using a questionnaire survey administered on site. No monetary incentives were given for participation.

\section{Measures}

\section{Job Design}

The two job design measures, job control and problem demands, used items from the scales developed by Jackson et al. (1993). Job control was a three-item measure that assessed the extent to which employees have discretion over methods used. A sample item is "Can you decide how to go about getting your job done?" (see Appendix for full list of items). The internal consistency (Cronbach's $\alpha$ ) was 0.83. Problem demand was a three-item measure. A sample item is "Are you required to deal with problems which are difficult to solve?" and Cronbach's $\alpha$ was 0.86 . For both variables, a five-point response scale was used $(1=$ not $a$ lot to $5=$ a great deal).

\section{Work-Based Learning Strategies}

The two work-based learning strategy measures used items from scales developed by Holman et al. (2001). The cognitive work-based learning strategy measure was an eightitem measure that assessed the extent to which employees used organization learning strategies (Example item, "I work out which of the key points of my job are important and which are less important") and elaboration learning strategies (Example item, "I try to understand the 
implications of new information I receive for XXX as a company"). Cronbach's $\alpha=0.87$. Behavioral work-based learning was a seven-item measure covering the extent to which employees gained information from others (Example item, "I ask others for more information when I need"), from written material (Example item, "I fill in the gaps in my knowledge by getting hold of appropriate material") and through practical application (Example item, "I do practical things to help myself to learn"). Cronbach's $\alpha=0.86$. Items were measured on a five-point scale from "Not at all" to "A great deal."

\section{Innovation Process}

As our theoretical model specified three separate components of innovation, we had to develop an measure that distinguished between them. Other measures only cover a limited number of components (e.g., idea generation, Oldham and Cummings 1996; idea generation and suggestion making, Axtell et al. 2000) or are a single global measure that combines separate components (Burningham and West 1995; Janssen 2000, 2001, 2005).

To develop an innovation measure, three items on each of the three components of innovation (idea generation, idea promotion, and idea implementation) were generated by two of the authors (see Table 1) and their face validity checked by other University research staff and a senior manager from the study organization. For each item respondents were asked the extent to which they had done this within the last year. A five-point response scale was used $(1=$ not a lot to $5=$ a great deal). To investigate the convergent and discriminant factorial validity of the proposed three-factor structure, we used Mplus (Muthén and Muthén 2004) to conduct a confirmatory factor analysis on the full sample and compared this against a one-factor and two-factor model. To assess model fit it is generally recommended that a range of fit indices are used (Chen et al. 2008). For confirmatory factor analysis, Mplus provides the $\chi^{2}$ statistic, RMSEA, the standardized root mean squared residual (SRMR) and the comparative fit index (CFI). Benchmarks for a good model fit are indicated by values of RMSEA $<0.06$, RMR $<0.08$, SRMR $<0.06$, and CFI $>$ 0.95 (Hu and Bentler 1999). When comparing nested models we tested whether the change in $\chi^{2}$ was significant.

The three-factor model had an excellent level of fit $\left(N=327, \chi^{2}=61.52\right.$, df $=24$; RMSEA $=0.07$; SRMR $=$ 0.03; CFI $=0.99$ ) and was a significantly better fit than the two-factor model $\left(\chi^{2}=336.77\right.$, $\mathrm{df}=26$; RMSEA $=$ $0.19 ; \mathrm{SRMR}=0.06 ; \mathrm{CFI}=0.89 ; \Delta \chi^{2}=275.25, \mathrm{df}=1$, $p<0.01)$ and the one-factor model $\left(\chi^{2}=909.90\right.$, df $=27 ; \quad$ RMSEA $=0.32 ; \quad$ SRMR $=0.09 ; \quad$ CFI $=0.71$; $\Delta \chi^{2}=848.38$, df $\left.=1, p<0.01\right)$. Evidence for convergent factorial validity of the three-factor model is shown by each item indicator being significantly related to the underlying latent factor and all coefficients were above $0.82(p<0.01)$ (see Table 1$)$. With regard to discriminant factorial validity, the latent factor correlations were idea generation and promoting suggestions, $\varphi=0.76$, $p<0.01$; idea generation and idea implementation $\varphi=0.59, p<0.01$; and promoting suggestions and idea implementation $\varphi=0.73, p<0.01$. Although high, these latent factor correlations are well below the 0.85 recommended cut-off point (Kline 1998) and none of the confidence intervals (CIs) between the latent construct correlations included 1.00, indicating that they are discrete constructs (Anderson and Gerbing 1988). The internal consistencies of the derived subscales were; idea generation $\alpha=0.90$; promoting suggestions, $\alpha=0.93$; and, idea implementation, $\alpha=0.95$. These results suggest that the tripartite measure of the innovation process is reliable and has a good convergent and discriminant factorial validity.

\section{Other Variables}

Following the recommendations of Becker (2005) on the selection of control variables, a review of the literature (e.g., Ella et al. 2004; Janssen and Van Yperen 2004; Janssen 2005; Hirst et al. 2009; Scott and Bruce 1994) indicated that age and gender had the most consistent associations with innovation behavior. These two variables were therefore included as controls. Gender was a dummy variable $($ Male $=0)$. We also included a measure of employee contentment in order to meet the conditions for testing mediation as set out by Iacobucci et al. (2007), which is described in more detail later. Employee contentment was a three-item measure of employee well-being (Warr 1990). For each item (contentment, calmness, and relaxed), participants were asked to rate the extent to which they had experienced that type of affect in the last month. A five-point response scale was used ("never" to "all of the time") and Cronbach's $\alpha=0.87$.

We ran a CFA including all the main study variables and this showed good model fit $\left(N=327, \chi^{2}=807.12\right.$, $\mathrm{df}=468 ; \mathrm{RMSEA}=0.05 ; \mathrm{SRMR}=0.05 ; \mathrm{CFI}=0.95)$, indicating that each measure had a good level of convergent and discriminant factorial validity.

\section{Analytical Strategy for Hypothesis Testing}

To test our hypotheses concerning direct and mediated effects, we followed the procedure set out by Iacobucci et al. (2007) for testing mediation using structural equation modeling (Judd and Kenny 1981). The first stage of this procedure involves testing a model that includes both direct and indirect effects, so as to test for each effect while 
Table 1 Items for employee innovation behavior measure and parameter estimates and $R^{2}$ from CFA for three-factor model using full sample

\begin{tabular}{lll}
\hline & \multicolumn{2}{l}{ Three-factor model } \\
\cline { 2 - 3 } & $\begin{array}{l}\text { Standardized } \\
\text { parameter estimate }\end{array}$ & $R^{2}$ \\
\hline $\begin{array}{l}\text { Idea generation } \\
\text { 1. Thought of new ideas }\end{array}$ & 0.91 & 0.83 \\
2. Had ideas about how things might & 0.90 & 0.82 \\
$\quad$ be improved & & 0.70 \\
3. Found new ways of doing things & 0.84 & 0.77 \\
$\begin{array}{l}\text { Idea promotion } \\
\text { 4. Attempted to get support from } \\
\quad \text { others for your ideas }\end{array}$ & 0.88 & 0.79 \\
$\begin{array}{l}\text { 5. Tried to get approval for } \\
\text { improvements you suggested }\end{array}$ & 0.89 & 0.86 \\
$\begin{array}{l}\text { 6. Got involved in persuading others to } \\
\text { adopt your proposals for doing } \\
\text { things differently }\end{array}$ & 0.93 & \\
$\begin{array}{l}\text { Idea implementation } \\
\text { 7. Had your ideas implemented } \\
\text { 8. Had your suggestions for } \\
\quad \text { improvements adopted }\end{array}$ & 0.94 & 0.88 \\
$\begin{array}{l}\text { 9. Had your proposals for doing things } \\
\text { differently carried out }\end{array}$ & 0.93 & 0.91 \\
\hline
\end{tabular}

controlling for the others. Model 1 (see Fig. 1) therefore included indirect paths (i.e., from each job design variable to each learning strategy, and from each learning strategy to each innovation measure) and direct paths (i.e., from each job design variable to each innovation measure). Iacobucci et al. also recommend that the model includes one or more other variables (either an antecedent or consequence of the variables in the structural model) to make it less plausible that other rival explanations might explain the results and also to yield sufficient degrees of freedom to test for mediation. Based on existing theories of job design, learning, and well-being (Holman and Wall 2002), we therefore added a measure of employee contentment as an outcome of job design and learning strategies. We also added age and gender as controls.

The second stage in the mediation testing procedure involves calculating the significance of the indirect effect. To do this, we used the bootstrapping procedure recommended by Preacher and Hayes $(2004,2008)$, as it has been shown to have higher power while maintaining reasonable control over the Type I error rate than other mediation testing procedures, e.g., the Sobel test (MacKinnon et al. 2002). Five thousand resamples of the data were used to estimate the indirect effect. A significant mediated effect is indicated by a point estimate of the product of coefficient that has bias corrected $95 \%$ CIs in which the upper or lower bounds do not include zero. The third stage involves calculating the proportion of variance in the dependent variables that is explained by the indirect effects. The final stage of this procedure involves testing models with alternative causal paths. We therefore created a alternative models, one in which the innovation measures were the independent variables, the learning strategies were the mediating variables and the job design variables were the dependent variables (Model 2); and a model in which the learning strategy measures were the independent variables, the innovation measures were the mediating variables and the job design variables were the dependent variables (Model 3). If these alternative models show nonsignificant relationships between key paths, then the hypothesized model can be preferred.

\section{Results}

Descriptive statistics and correlations of the study variables are shown in Table 2. All hypotheses were tested using Model 1, which displayed a good fit to the data, $N=327$, $\chi^{2}=881.68 .76, \quad \mathrm{df}=522 ; \quad \mathrm{RMSEA}=0.05 ;$ SRMR $=$ 0.05 ; CFI $=0.95$. The results from Model 1 fully confirmed Hypothesis 1, as job control had a direct positive association with cognitive work-based learning strategies ( $\beta=0.19, p<0.05)$ and behavioral work-based learning strategies $(\beta=0.18, p<0.05)$, while problem demand had a direct positive association with cognitive work-based learning strategies $(\beta=0.37, p<0.01)$ and behavioral work-based learning strategies $(\beta=0.31, p<0.01)$.

Hypotheses 2-4 concerned the relationship between learning strategies and innovation. Hypothesis 2 was fully confirmed as cognitive work-based learning strategies ( $\beta=0.19, p<0.01)$ and behavioral work-based learning strategies $(\beta=0.20, p<0.01)$ had direct positive associations with employee idea generation. Hypotheses 3 and 4 were not confirmed as cognitive work-based learning strategies were not significantly associated with idea promotion $(\beta=-0.05$, n.s. $)$ or idea implementation $(\beta=$ $-0.01, n . s$.$) , and behavioral work-based learning strategies$ were not significantly associated with idea promotion ( $\beta=0.04$, n.s. $)$ or idea implementation $(\beta=-0.05$, n.s. $)$.

Hypothesis 5 stated that work-based learning strategies will mediate the relationship between job control and each of the innovation variables, while Hypothesis 6 stated that work-based learning strategies will mediate the relationship between problem demand and each of the innovation variables. However, as learning strategies were only significantly related to idea generation, we could only test for indirect effects with regard to this outcome. The results of the bootstrapping procedure to test for indirect effects revealed that all were significant, as none had CIs that passed through zero (see Table 3), and that all four indirect 
Table 2 Correlations, means, and standard deviations for the main study variables $(N=327)$

\begin{tabular}{|c|c|c|c|c|c|c|c|c|c|c|c|}
\hline & M & SD & 1 & 2 & 3 & 4 & 5 & 6 & 7 & 8 & 9 \\
\hline 1. Job control & 3.28 & 0.97 & - & & & & & & & & \\
\hline 2. Problem demand & 2.65 & 1.19 & 0.31 & - & & & & & & & \\
\hline 3. Cognitive learning strategies & 3.04 & 0.70 & 0.32 & 0.44 & - & & & & & & \\
\hline 4. Behavioral learning strategies & 3.04 & 0.69 & 0.32 & 0.47 & 0.55 & - & & & & & \\
\hline 5. Idea generation & 2.20 & 0.92 & 0.27 & 0.57 & 0.43 & 0.51 & - & & & & \\
\hline 6. Idea promotion & 2.19 & 1.07 & 0.32 & 0.55 & 0.46 & 0.43 & 0.70 & - & & & \\
\hline 7. Idea implementation & 1.88 & 1.00 & 0.24 & 0.40 & 0.27 & 0.30 & 0.56 & 0.68 & - & & \\
\hline 8. Age & 37.32 & 9.23 & 0.01 & -0.12 & 0.02 & -0.15 & -0.08 & -0.01 & 0.08 & - & \\
\hline 9. Gender $($ Male $=0)$ & 0.03 & 0.16 & 0.16 & 0.12 & 0.13 & 0.10 & 0.07 & 0.12 & 0.12 & -0.09 & - \\
\hline 10. Contentment & 3.34 & 0.95 & 0.07 & -0.08 & 0.09 & 0.08 & 0.01 & -0.08 & 0.05 & 0.10 & -0.01 \\
\hline
\end{tabular}

Note: Correlations over 0.11 significant at $p<0.05$, and correlations over 0.15 significant at $p<0.01$

Table 3 Bootstrapping analysis of indirect effects

\begin{tabular}{|c|c|c|c|}
\hline \multirow[t]{2}{*}{ Mediation } & \multirow[t]{2}{*}{$\begin{array}{l}\text { Point } \\
\text { estimate }\end{array}$} & \multicolumn{2}{|c|}{$\begin{array}{l}95 \% \\
\text { Confidence } \\
\text { interval }\end{array}$} \\
\hline & & Lower & Upper \\
\hline \multicolumn{4}{|l|}{ 1. Job control to idea generation } \\
\hline Total indirect effect & 0.08 & 0.02 & 0.17 \\
\hline $\begin{array}{l}\text { Job control-cognitive strategies-idea } \\
\text { generation }\end{array}$ & 0.04 & 0.01 & 0.11 \\
\hline $\begin{array}{l}\text { Job control-behavioral strategies-idea } \\
\text { generation }\end{array}$ & 0.04 & 0.01 & 0.10 \\
\hline \multicolumn{4}{|l|}{ 2. Problem demand to idea generation } \\
\hline Total indirect effect & 0.10 & 0.05 & 0.16 \\
\hline $\begin{array}{l}\text { Problem demand-cognitive } \\
\text { strategies-idea generation }\end{array}$ & 0.05 & 0.02 & 0.10 \\
\hline $\begin{array}{l}\text { Problem demand-behavioral } \\
\text { strategies-idea generation }\end{array}$ & 0.05 & 0.01 & 0.11 \\
\hline $\begin{array}{l}\text { 3. Idea generation-idea promotion-idea } \\
\text { implementation }\end{array}$ & 0.42 & 0.28 & 0.58 \\
\hline
\end{tabular}

effects explained $32.6 \%$ of the variance in idea generation. The total indirect effect between job control and idea generation was 0.08 (95\% CI 0.02-0.17), while the specific indirect effect through cognitive strategies was $0.04(95 \%$ CI $0.01-0.11$ ), which explained $7.1 \%$ of the variance in idea generation. The specific indirect effect through behavioral strategies was 0.04 (95\% CI 0.01-0.10), which explained $6.8 \%$ of the variance in idea generation. The total indirect effect from problem demand to idea generation was 0.10 (95\% CI 0.05-0.16) and the specific indirect effect through cognitive strategies was 0.05 (95\% CI $0.02-0.10$ ), which explained $10.1 \%$ of the variance in idea generation. The specific indirect effect through behavioral strategies was 0.05 (95\% CI 0.01-0.11), which explained $8.6 \%$ of the variance in idea generation. These results suggest that the effects of job control on idea generation are mediated by work-based learning strategies and that the effects of problem demand on idea generation are partially mediated by work-based learning strategies because of the significant direct association between problem demand and idea generation $(\beta=0.38, p<0.01)$. The analysis of Model $2 \quad\left(\chi^{2}=876.54, \quad \mathrm{df}=520 ; \quad\right.$ RMSEA $=0.05$; SRMR $=0.05 ; \mathrm{CFI}=0.95)$ and Model $3\left(\chi^{2}=876.59\right.$, $\mathrm{df}=520 ;$ RMSEA $=0.05 ;$ SRMR $=0.05 ;$ CFI $=0.95)$, which had reversed causal paths, provides some support that causal direction assumed in Model 1 is correct, as these alternative models both showed that when job design was included as an outcome of learning strategies, only one of the three relationships was significant, that from cognitive work-based learning strategies to problem demand.

We also conducted some supplementary analyses. First, we examined the relationships between the different components of the innovation process. There was a significant relationship between idea generation and idea promotion $(\beta=0.64, p<0.01)$ and between idea promotion and idea generation $(\beta=0.64, p<0.01)$ (see Fig. 1). Further analysis revealed that idea promotion mediated the relationship between idea generation and idea implementation, with the point estimate of the total indirect effect being 0.42 (95\% CI 0.28-0.58) (see Table 3). Second, we examined whether job control moderated the effects on job demands on each learning strategy, which is line with the job demands control model (Karasek and Theorell 1990), but failed to find significant interaction effects.

Finally, as all the measures were self-report from a single survey, we followed the procedure for testing for common method variance recommended by Podsakoff et al. (2003) which involves adding a latent common method variable to the final model. An improvement in model fit is not uncommon when adding a common method factor (Doty and Glick 1998; Meade et al. 2007). However, 
if this occurs and the significance of the substantive relationships in a model remain unchanged, then any evidence for common method variance does not invalidate the findings (Podsakoff et al. 2000; Spector 2006). In this study, the addition of a common methods factor marginally improved model fit $\left(\chi^{2}=756.13, \mathrm{df}=492\right.$; RMSEA $=$ 0.05 ; SRMR $=0.05 ; \mathrm{CFI}=0.96$ ) but the significance of all paths was unchanged. This finding suggests that common method variance does not unduly affect the study's findings.

\section{Discussion}

Our study set out to develop and test a theoretical model of the job design-learning mechanism in relation to employee innovation. A central proposition of the model was confirmed, namely that work-based learning strategies mediate the relationship between job characteristics and idea generation. Our findings make a number of important contributions.

The first contribution is with regard to the job design literature and, in particular, the job design-learning mechanism. While previous studies have provided support for the job design-learning mechanism in relation to job performance and employee well-being (e.g., Holman and Wall 2002; Taris and Kompier 2005; Taris and Schreurs 2009; Wall et al. 1992), this study extends support for this idea in relation to innovation, and specifically, idea generation. The study shows that job design characteristics are important antecedents of learning and employee innovation. Job control and problem demand were found to be associated positively and independently with learning strategies and to be indirectly associated with idea generation through learning strategies, while problem demand also had a direct association with idea generation and idea promotion. An implication is that jobs with high levels of problem demand or job control might be the most suitable for fostering learning and idea generation. However, while job control appears to have a generally positive relationship with learning not all types of job demand may foster learning (Taris and Kompier 2005; Taris and Schreurs 2009). For example, while workplace learning may be promoted by challenge demands such as problem demand, future studies should examine whether learning is inhibited by hindrance demands, i.e., demands appraised by employees as potentially constraining their personal development and work-related accomplishment (Podsakoff et al. 2007). This suggests that future research in this area needs to examine a wider range of job design characteristics than job control and problem-solving demand and to include those that may influence the opportunity to use and acquire knowledge (e.g., variety, feedback, and social interdependence) and those that may influence the need to use and acquire knowledge (e.g., workload and emotion demands). Future research also needs examine the alternative mechanisms through which job design might affect employee innovation, such as motivation or affect (Parker and Wall 1999), to provide a better estimation of the relative importance of the role of learning in the relationship between job design and innovation. For example, many job design characteristics are known to affect intrinsic motivation which in turn may make employees more persistent when searching for new ideas or implementing an idea (Humphrey et al. 2007). Job design characteristics are also known to influence employee affect, which has been shown be associated with idea generation (Amabile et al. 2005; George and Zhou 2002) and prosocial behaviors that might include promoting suggestions and taking the time to implement a new and useful idea (Lee and Allen 2002).

Our findings also contribute to the understanding of job design by illuminating how job characteristics are associated with the process of learning. Previous studies in this area have examined learning by measuring learning-related constructs such as self-efficacy, skill utilization, and learning opportunities (Holman and Wall 2002; Parker and Sprigg 1998), as well as indicators of knowledge acquisition such as fault reduction (Wall et al., 1992). Our inclusion of learning strategies makes this the first study to directly examine the exact type of learning behaviors or tactics (Porath and Bateman 2006) that employees might use in response to the job context. However, an implicit assumption in this study is that the use of learning strategies results in knowledge acquisition. Clearly, future studies on job design and learning strategies would benefit from measuring knowledge acquisition, although this is extremely difficult in practice as employees develop knowledge on many different topics and from different starting points.

Another contribution of this study is with regard to the literature on learning and innovation in organizations. Recall that a theoretical assumption of this literature is that the learning process increases domain-related knowledge, which in turn increases a person's potential to combine information in novel ways and generate new ideas (Amabile 1996; Hayes 1989). Our findings are not only in keeping with this theoretical argument, but also demonstrate for the first time that an important element of the learning process, learning strategies, is related to idea generation. These results compliment other studies of learning and innovation which have focused on the role of learning goal orientation, a dispositional personality characteristic concerning an individual's motivational orientation and beliefs in achievement situations (Dweck 1999; Elliot and McGregor 2001). For example, Hirst et al. (2009) found a positive direct relationship between 
learning orientation and idea generation. It is argued that these relationships occur because, when faced with a challenging task, individuals with a high learning goal orientation tend to take an intrinsic interest in the task, adopt cognitive strategies aimed at understanding and mastery, and are motivated to develop new skills.

This study found no evidence that work-based learning strategies were directly associated with idea promotion or idea implementation, nor did it find that job control was directly associated with these aspects of the innovation process, while problem demand was similarly unrelated to idea implementation. These findings suggest that the effects of job design and learning strategies may be strongest on idea generation and that social factors, such as social support from colleagues, may play a more important role in facilitating a person to promote an idea and in getting an idea implemented (Axtell et al. 2000).

Although direct and mediated relationships between constructs were the main focus in this study, it is important to recognize the potential effects of individual and contextual moderators on these relationships. One important individual moderator could be an extensive pre-existing knowledge base, which may enhance the effect of learning strategies on idea generation, as it might enable employees to understand more readily the implications of new knowledge. One important contextual moderator could be the role of the team leader in setting norms and expectations with regard to learning and innovation. When a team leader sets high expectations about engaging in learning activities (Bezuijen et al. 2009), employee learning strategy use may be higher in response to job demands then when team leaders do not have such expectations. Thus, it could have been the case that we found positive results in this sample because employees had an extensive knowledge base and that team leaders set high expectations regarding engaging in learning and innovation activities.

A key implication of this study for organizational practice is that the innovation process, and in particular idea generation, can be stimulated by increasing job control and problem demand. Practically, this can be achieved by extending the scope, complexity and variety of tasks in an employee's job, and by allowing employees greater discretion in how they manage and complete tasks. A further practical implication is that organizations can encourage employees to use and develop cognitive and behavioral learning strategies as a means of stimulating idea generation. One possible means of achieving this is to use experiential and problem-based training methods, as research in the educational field shows that these methods can promote the use of effective learning strategies (Entwistle and Peterson 2004). A further implication of our findings is that organizations may not be able to rely solely on the capabilities of employees or effective job design to promote the later phases on the innovation process, i.e., idea promotion and idea implementation. Rather this study, combined with the evidence from other studies (e.g., Axtell et al. 2000; Janssen 2005; Scott and Bruce 1994), suggests that organizations need to focus on leadership and social practices and systems to facilitate the later stages of the innovation process.

Although there are a number of strengths to this study, such as the use of structural equation modeling to simultaneously test the effects of job design on learning and innovation and the effects of different mediating paths, and the use of bootstrapping to test for mediating effects, there are a number of limitations. First, the study was based on a cross-sectional sample, meaning that the results cannot be interpreted causally and that the real direction of effect could be counter to that hypothesized. However, alternative models did not provide strong evidence for reversed paths, and longitudinal research on the relationship between job design and learning suggests that the proposed direction of causality is correct and that any reverse paths are relatively weak (de Lange et al. 2004; Holman and Wall 2002), all of which suggests that the causal direction assumed in this article should be preferred. Common method variance may also have been a problem, as all measures were self-report such that future studies in this area would benefit from including objective measures; although the results of the common method factor latent factor analysis and the existence of zero-order path coefficients provides some confidence that common method variance did not affect the findings unduly. A further limitation was the innovation measure. Although it included many important aspects of the innovation process, future research on learning and employee innovation could also include items on idea realization (e.g., evaluating the utility of ideas) and gaining support from others (Janssen 2000; Rank et al. 2004), and the extent to which ideas are considered by others in the organization as useful or not, since innovation may not always be functional (Anderson and Gasteiger 2007).

Another potential limitation is that the majority of the sample were shop floor manufacturing workers who, it can be suggested, might have little opportunity to engage in innovative behavior or have jobs with few problems needing to be addressed, and thus it was not a good sample in which to test the hypotheses. However, as noted earlier, all employees had the opportunity to engage in the innovation process through, for example, participation in a continuous improvement program. Moreover, the mean level of job control indicated that employees reported a moderate level of job control, implying that employees were not so constrained in their job that they had no opportunity to engage in the innovation process. In addition, although the mean level of problem demand implies that employees typically experienced a moderate to a little 
amount of problem demand, the fact that we found significant relationships between problem demand and learning strategies, as well as idea generation and idea promotion, does indicate that there was sufficient variability in problem demand in this context. Furthermore, our results show how important problem demand is with regard to learning and innovation, as the low level of problem demand maybe one of the reasons why innovation was relatively low in this context. These factors suggest that the sample was an adequate one in which to test the hypotheses. However, the replication of these findings in larger samples of different occupational groups and with more women would help to establish the generalizability of the results.

In conclusion, this study has extended our understanding of the job design-learning mechanism and provided a theoretical framework of the relationship between job design, learning and innovation. This framework can guide future work in this area, which could concentrate on the role of individual traits such as goal orientation, and include a wider set of job and organizational variables. Such an approach would develop a deeper and more nuanced understanding of the job design-learning mechanism.

\section{Appendix: Items of Other Study Measures}

\section{Job Control}

To what extent:

1. Do you plan your own work?

2. Can you choose the methods to use in carrying out your work?

3. Can you decide how to go about getting your job done?

\section{Problem Solving Demand}

To what extent:

1. Are you required to deal with problems which are difficult to solve?

2. Do you have to solve problems which have no obvious correct answer?

3. Do you come across problems in your job that you have not met before?

Learning Strategies

\section{Cognitive Learning Strategies}

To what extent do you do the following?
1. I think about how my work fits into the "bigger picture" at [name of organization].

2. I try to think how the different parts of [name of organization] fit together.

3. I try to think how my work relates to that of others at [name of organization].

4. I try to understand the implications of new information I receive for [name of organization] as a company.

5. I try to develop an overall idea of how the different parts of my job fit together.

6. I work out which are the key points of my job and which are less important.

7. I generally try to understand how new information fits into how I do my job.

8. I think about new information and its implications for my job rather than merely concentrating on the facts we are given.

\section{Behavioral Learning Strategies}

To what extent do you do the following?

1. I try out new things by applying them in practice.

2. I do practical things to help myself to learn.

3. I ask others questions when I am uncertain about something.

4. I get someone to help me when I need assistance.

5. I ask others for more information when I need it.

6. When I am unsure about something I look it up.

7. I fill in the gaps in my knowledge by getting hold of appropriate material.

\section{References}

Amabile, T. M. (1983). The social psychology of creativity: A componential conceptualization. Journal of Personality and Social Psychology, 45, 357-376.

Amabile, T. M. (1988). A model of creativity and innovation in organizations. In B. M. Staw \& L. L. Cummins (Eds.), Research in organizational behavior (Vol. 10, pp. 123-167). Greenwich, CT: JAI Press.

Amabile, T. M. (1996). Creativity in context. Boulder, CO: Westview Press.

Amabile, T. M., Barsade, S. G., Mueller, J. S., \& Staw, B. M. (2005). Affect and creativity at work. Administrative Science Quarterly, 50, 367-403.

Amabile, T. M., \& Gryskiewski, S. S. (1987). Creativity in the $R \& D$ laboratory. Technical report no. 30. Greensborogh, NC: Centre for Creative Leadership.

Anderson, N., \& Gasteiger, R. M. (2007). Helping creativity and innovation thrive in organizations: Functional and dysfunctional perspectives. In J. Langan-Fox, C. L. Cooper, \& R. J. Klimoski (Eds.), Research companion to the dysfunctional workplace: Management challenges and symptoms (pp. 422-440). Cheltenham: Edward Elgar. 
Anderson, J. C., \& Gerbing, D. W. (1988). Structural equation modeling in practice: A review and recommended two-step approach. Psychological Bulletin, 103, 411-423.

Axtell, C. M., Holman, D. J., Unsworth, K., Wall, T. D., Waterson, P. E., \& Harrington, E. (2000). Shopfloor innovation: Facilitating the suggestion and implementation of ideas. Journal of Occupational and Organizational Psychology, 73, 265-285.

Bandura, A. (1986). Social foundations of thought and action: A social cognitive theory. Englewood Cliffs: Prentice-Hall.

Bandura, A. (1997). Self-efficacy: The exercise of control. New York: Freeman.

Becker, T. E. (2005). Potential problems in the statistical control of variables in organizational research: A qualitative analysis with recommendations. Organizational Research Methods, 8, 274-289.

Bezuijen, X. M., van den Berg, P. T., van Dam, K., \& Thierry, H. (2009). Pygmalion and employee learning: The role of leader behaviors. Journal of Management, 35, 1248-1267.

Bond, F. W., \& Flaxman, P. E. (2006). The ability of psychological flexibility and job control to predict learning, job performance, and mental health. Journal of Organizational Behavior Management, 26, 113-130.

Borgatti, S. P., \& Cross, R. (2003). A relational view of information seeking and learning in social networks. Management Science, $49,432-445$.

Burke, M. J., \& Day, R. (1986). A cumulative study of the effectiveness of managerial training. Journal of Applied Psychology, 71, 232-245.

Burningham, C., \& West, M. A. (1995). Individual, climate and group interaction process as predictors of work team innovation. Small Group Research, 26, 106-117.

Burt, R. S. (2004). Structural holes and good ideas. American Journal of Sociology, 110, 349-399.

Cavanaugh, M. A., Boswell, W. R., Roehling, M. V., \& Boudreau, J. W. (2000). An empirical examination of self-reported work stress among U.S. managers. Journal of Applied Psychology, 85, $65-74$.

Chen, F., Curran, P. J., Bollen, K. A., Kirby, J., \& Paxton, P. (2008). An empirical evaluation of the use of fixed cutoff points in RMSEA test statistic in structural equation models. Sociological Methods Research, 36, 462-494.

Christiaans, H., \& Venselaar, K. (2005). Creativity in design engineering and the role of knowledge: Modelling the expert. International Journal of Technology and Design Education, 15, 217-236.

Craik, F. (2002). Levels of processing: Past, present, and future? Memory, 10, 305-318.

Daniels, K., Boocock, G., Glover, J., Hartley, R., \& Holland, J. (2009). An experience sampling study of learning, affect and the demands control support model. Journal of Applied Psychology, 4, 1003-1017.

Dansereau, D. F. (1985). Learning strategy research. In J. W. Segal, S. F. Chipman, \& R. Glaser (Eds.), Thinking and learning skills (Vol. 1, pp. 209-239). Hillsdale, NJ: Erlbaum.

De Lange, A. H., Taris, T. W., Kompier, M. A. J., Houtman, I. L. D., \& Bongers, P. M. (2004). Work characteristics and psychological well-being: Testing normal, reversed and reciprocal relationships within the 4-wave SMASH study. Work and Stress, 18, 149-166.

Doty, D. H., \& Glick, W. H. (1998). Common methods bias: Does common methods variance really bias results? Organizational Research Methods, 1, 374-406.

Driskell, J., Copper, C., \& Moran, A. (1994). Does mental practice enhance performance. Journal of Applied Psychology, 79, 481-492.

Dweck, C. S. (1999). Self-theories: Their role in motivation, personality, and development. Ann Arbor, MI: Psychology Press, Taylor \& Francis Group.
Ella, M., Erez, M., \& Naveh, E. (2004). Do personal characteristics and cultural values that promote innovation, quality, and efficiency compete or complement each other? Journal of Organizational Behavior, 25, 175-199.

Elliot, A. J., \& McGregor, H. A. (2001). A $2 \times 2$ achievement goal framework. Journal of Personality and Social Psychology, 80, 501-514.

Entwistle, N. J. (2000). Approaches to studying and levels of understanding: The influences of teaching and assessment. In J. C. Smart (Ed.), Higher education: Handbook of theory and research (Vol. XV). New York: Agathon Press.

Entwistle, N. J., \& Peterson, E. R. (2004). Conceptions of learning and knowledge in higher education: Relationships with study behaviour and influences of learning environments. International Journal of Educational Research, 41, 407-428.

Ericsson, K. A. (1998). The scientific study of expert levels of performance: General implications for optimal learning and creativity. High Ability Studies, 9, 75-100.

Farr, J. L. (1990). Facilitating individual role innovation. In M. A. West \& J. L. Farr (Eds.), Innovation and creativity at work: Psychological and organizational strategies (pp. 207-230). Chichester: Wiley.

Fisher, S. L., \& Ford, J. K. (1998). Differential effects of learner effort and goal orientation on two learning outcomes. Personnel Psychology, 51, 397-420.

Frese, M., \& Zapf, D. (1994). Action as the core of work psychology: A German approach. In H. C. Triandis, M. D. Dunnette, \& L. M. Hough (Eds.), Handbook of industrial and organizational psychology (Vol. 4, pp. 271-340). Palo Alto, CA: Consulting Psychologists Press.

George, J. M., \& Zhou, J. (2002). Understanding when bad moods foster creativity and good ones don't: The role of context and clarity of feelings. Journal of Applied Psychology, 87, 687-697.

Gist, M. E., \& Mitchell, T. R. (1992). Self-efficacy: A theoretical analysis of its determinants and malleability. Academy of Management Review, 17, 183-211.

Hacker, W., Skell, W., \& Straub, W. (1968). Arbeitpsychologie und wissenshaftlich-technische revolution [Work psychology and the scientific-technical revolution]. Berlin: Deutscher Verlag der Wissenschaften.

Hackman, J. R., \& Oldham, G. (1980). Work re-design. Reading, MA: Addison-Wesley.

Hayes, J. R. (1989). Cognitive processes in creativity. In J. A. Glover, R. R. Ronning, \& C. R. Reynolds (Eds.), Handbook of creativity (pp. 135-146). New York: Plenum Press.

Hirst, G., Van Knippenberg, D., \& Zhou, J. (2009). A cross-level perspective on employee creativity: goal orientation, team learning behavior, and individual creativity. Academy of Management Journal, 52, 280-293.

Hockey, G. R. J. (1997). Compensatory control in the regulation of human performance under stress and high workload: A cognitive-energetical framework. Biological Psychology, 45, 73-93.

Holman, D., Epitropaki, O., \& Fernie, S. (2001). Understanding learning strategies in the workplace: A factor analytic investigation. Journal of Occupational and Organizational Psychology, $74,675-682$.

Holman, D. J., \& Wall, T. D. (2002). Work characteristics, learningrelated outcomes, and strain: A test of competing direct effects, mediated, and moderated models. Journal of Occupational Health Psychology, 7, 283-301.

Hu, L., \& Bentler, P. M. (1999). Cutoff criteria for fit indexes in covariance structure analysis: Conventional criteria versus new alternatives. Structural Equation Modelling, 6, 1-55.

Humphrey, S. E., Nahrgang, J. D., \& Morgeson, F. P. (2007). Integrating motivational, social, and contextual work design features: A meta-analytic summary and theoretical extension of 
the work design literature. Journal of Applied Psychology, 92, 1332-1356.

Iacobucci, D., Saldanha, N., \& Deng, X. (2007). A meditation on mediation: Evidence that structural equations models perform better than regressions. Journal of Consumer Psychology, 17, 139-153.

Jackson, P. R., Wall, T. D., Martin, R., \& Davids, K. (1993). New measures of job control, cognitive demand and production responsibility. Journal of Applied Psychology, 78, 753-762.

Janssen, O. (2000). Job demands, perceptions of effort-reward fairness, and innovative work behaviour. Journal of Occupational and Organizational Psychology, 73, 287-302.

Janssen, O. (2001). Fairness perceptions as a moderator in the curvilinear relationships between job demands, and job performance and job satisfaction. Academy of Management Journal, 44, 1039-1050.

Janssen, O. (2005). The joint impact of perceived influence and supervisor supportiveness on employee innovative behaviour. Journal of Occupational and Organizational Psychology, 78, 573-579.

Janssen, O., \& Van Yperen, N. W. (2004). Employees' goal orientations, the quality of leader-member exchange, and the outcomes of job performance and job satisfaction. Academy of Management Journal, 47, 368-384.

Judd, C. M., \& Kenny, D. A. (1981). Process analysis: Estimating mediation in treatment evaluations. Evaluation Review, 5, 602-619.

Kanter, E. (1988). When a thousand flowers bloom: Structural collective and social conditions for innovation in organizations. Research in Organizational Behavior, 10, 169-211.

Karasek, R. (1979). Job demands, job decision latitude, and mental strain: Implications for job redesign. Administrative Science Quarterly, 24, 285-307.

Karasek, R. A., \& Theorell, T. (1990). Healthy work: Stress, productivity, and the reconstruction of working life. New York: Basic Books.

Kline, R. (1998). Principles and practice of structural equation modeling. New York: Guilford Press.

Kolb, A., \& Kolb, D. A. (2000). Bibliography of research on experiential learning theory and the learning style inventory. Cleveland, OH: Department of Organizational Behavior, Weatherhead School of Management, Case Western Reserve University.

Leach, D., Wall, T. D., \& Jackson, P. (2003). The effect of empowerment on job knowledge: An empirical test involving operators of complex technology. Journal of Occupational and Organisational Psychology, 76, 27-52.

Lee, K., \& Allen, N. J. (2002). Organizational citizenship behavior and workplace deviance: The role of affect and cognitions. Journal of Applied Psychology, 87, 131-142.

LePine, J. A., LePine, M. A., \& Jackson, C. L. (2004). Challenge and hindrance stress: Relationships with exhaustion, motivation to learn, and learning performance. Journal of Applied Psychology, 89, 883-891.

LePine, J. A., Podsakoff, N. P., \& LePine, M. A. (2005). A metaanalytic test of the challenge stressor-hindrance stressor framework: An explanation for inconsistent relationships among stressors and performance. Academy of Management Journal, 48, 764-775.

MacKinnon, D. P., Lockwood, C. M., Hoffman, J. M., West, S. G., \& Sheets, V. (2002). A comparison of methods to test mediation and other intervening variable effects. Psychological Methods, 7 , 83-104.

Marton, F., \& Saljo, R. (1976). On qualitative differences in learning I: Outcome and process. British Journal of Educational Psychology, 46, 4-11.
McCauley, C. D., Ruderman, M. N., Ohlott, P. J., \& Morrow, J. E. (1994). Assessing the developmental components of managerial jobs. Journal of Applied Psychology, 79, 544-560.

Meade, A. W., Watson, A. M., \& Kroustalis, C. M. (2007). Assessing common methods bias in organizational research. Paper presented at the 22nd annual meeting of the society for industrial and organizational psychology, New York.

Morgeson, F. P., \& Humphrey, S. E. (2006). The work design questionnaire (WDQ): Developing and validating a comprehensive measure for assessing job design and the nature of work. Journal of Applied Psychology, 91, 1321-1339.

Muthén, L. K., \& Muthén, B. O. (2004). Mplus: Statistical analysis with latent variables, users guide. Los Angeles: Muthén \& Muthén.

Oldham, G. R., \& Cummings, A. (1996). Employee creativity: Personal and contextual factors at work. Academy of Management Journal, 39, 607-634.

Parker, S. K., \& Sprigg, C. A. (1998). Minimizing strain and maximizing learning: The role of job demands, job control and pro-active personality. Journal of Applied Psychology, 84, 925-939.

Parker, S. K., \& Wall, T. D. (1999). Job and work design. London: Sage.

Pintrich, P. R. (2000). The role of goal orientation in self-regulated learning. In M. Boekaerts, P. R. Pintrich, \& M. Zeinder (Eds.), The handbook of self regulation (pp. 451-502). San Diego: Academic Press.

Pintrich, P. R., \& Garcia, T. (1993). Intra-individual differences in students' motivation and self-regulated learning. Zeitschrift fur Padagogische Psychologie, 7, 99-107.

Pintrich, P. R., Smith, D. A. F., Garcia, T., \& McKeachie, W. J. (1993). Reliability and predictive validity of the motivated strategies for learning questionnaire (MSLQ). Educational and Psychological Measurement, 53, 801-813.

Podsakoff, N. P., LePine, J. A., \& LePine, M. A. (2007). Differential challenge stressor-hindrance stressor relationships with job attitudes, turnover intentions, turnover, and withdrawal behavior: A meta-analysis. Journal of Applied Psychology, 92, 438-454.

Podsakoff, P. M., MacKenzie, S. B., Lee, J. Y., \& Podsakoff, N. P. (2003). Common method biases in behavioral research: A critical review of the literature and recommended remedies. Journal of Applied Psychology, 88, 879-903.

Podsakoff, P. M., MacKenzie, S. B., Paine, J. B., \& Bacharach, D. G. (2000). Organizational citizenship behaviors: A critical review of the theoretical and empirical literature and suggestions for future research. Journal of Management, 26, 513-563.

Porath, C. L., \& Bateman, T. S. (2006). Self-regulation: From goal orientation to job performance. Journal of Applied Psychology, 91, 185-192.

Preacher, K. J., \& Hayes, A. F. (2004). SPSS and SAS procedures for estimating indirect effects in simple mediation models. Behavior Research Methods, Instruments, and Computers, 36, 717-731.

Preacher, K. P., \& Hayes, A. F. (2008). Asymptotic and resampling strategies for assessing and comparing indirect effects in multiple mediator models. Behavior Research Methods, 40, 879-891.

Rank, J., Pace, V. L., \& Frese, M. (2004). Three avenues for future research on creativity, innovation, and initiative. Applied Psychology, 53, 518-528.

Renkl, A., \& Atkinson, R. K. (2003). Structuring the transition from example study to problem solving in cognitive skill acquisition: A cognitive load perspective. Educational Psychologist, 38, $15-22$.

Scott, S. G., \& Bruce, R. A. (1994). Determinants of innovative behavior: A path model of individual innovation in the workplace. Academy of Management Journal, 37, 580-607. 
Smith, E. R., \& DeCoster, J. (2000). Dual-process model in social and cognitive psychology: Conceptual integration and links to underlying memory system. Personality and Social Psychology Review, 4, 108-131.

Sonnentag, S., \& Kleine, B. M. (2000). Deliberate practice at work: A study with insurance agents. Journal of Organisational and Occupational Psychology, 73, 87-102.

Spector, P. (2006). Method variance in organizational research: Truth or urban legend? Organizational Research Methods, 9, 221-232.

Taris, T. W., \& Kompier, M. A. J. (2005). Job demands, job control, strain and learning behaviour: Review and research agenda. In A. S. Antoniou \& C. L. Cooper (Eds.), Research companion to organizational health psychology (pp. 132-150). Cheltenham, England: Elgar.

Taris, T. W., Kompier, M. A. J., De Lange, A. H., Schaufeli, W. B., \& Schreurs, P. J. G. (2003). Learning new behavior patterns: A longitudinal test of Karasek's active learning hypothesis among Dutch teachers. Work and Stress, 17, 1-20.

Taris, T. W., \& Schreurs, P. J. G. (2009). Explaining worker strain and learning: how important are emotional job demands? Anxiety, Stress and Coping, 22, 245-262.

Van de Ven, A., Angle, H., \& Poole, M. (Eds.). (1989). Research on the management of innovation: The Minnesota studies. New York: Harper \& Row.
Van den Broeck, A., De Cuyper, N., De Witte, H., \& Vansteenkiste, M. (2010). Not all job demands are equal: Differentiating job hindrances and job challenges in the job demands-resources model. European Journal of Work and Organizational Psychology, 6, 735-759.

Wall, T. D., Jackson, P. R., \& Davids, K. (1992). Operator work design and robotics system behavior: A serendipitous field study. Journal of Applied Psychology, 77, 353-362.

Warr, P. B. (1990). The measurement of well-being and other aspects of mental health. Journal of Occupational Psychology, 63, 193-210.

Warr, P. B., \& Allan, C. (1998). Learning strategies and occupational training. In C. L. Cooper \& I. T. Robertson (Eds.), International review of industrial and organizational psychology (Vol. 13, pp. 83-121). Chichester: Wiley.

Warr, P. B., \& Bunce, D. (1995). Trainee characteristics and the outcomes of open learning. Personnel Psychology, 48, 347-375.

Weisberg, R. W. (1999). Creativity and knowledge: A challenge to theories. In R. J. Sternberg (Ed.), Handbook of creativity (pp. 226-250). New York: Cambridge University Press. 